\title{
Measuring innovative practices for workplace safety, health and well-being in Tunisia during the COVID-19 pandemic
}

\author{
Hanen Khanchel* \\ IHEC, University of Carthage, Tunisia
}

Received 8 December 2020

Accepted 24 January 2021

\begin{abstract}
.
BACKGROUND: At the beginning of the health crisis, a growing number of Tunisian companies adopted innovative practices for organizing production and work associated with the spread of teleworking. These digital transformations correspond to both economic and social developments.

OBJECTIF: This study holds promise as an ergonomic device that may inform organizational orientations setting and guide future research around causal pathways influencing innovative practices implementation for workplace safety.

METHOD: Following the conclusions of Gallie and Zhou in 2013, [24] showing from a factorial analysis that the items selected belong to two dimensions, two health indicators were constructed from the answers to the following study.

RESULTS: The empirical analyzis performed on database of Best Places to Work confirms the structure of employee recognition expectation in Tunisia. This structure varies about the reconciliation between professional life and family. Then, the results of a mediation-moderation model highlight the decisive role of recognition in the construction of occupational health in the COVID-19 context, especially when greater involvement is expected from employees.

CONCLUSION: The innovative practices are applied in all regions of Tunisia at different levels and implemented at the first five certified companies to meet the various needs of employees. Its four pillars encompass social, mental, physical and financial well-being.
\end{abstract}

Keywords: Occupational health and safety, well-being, stakeholders, Human Resource management, COVID-19 pandemic

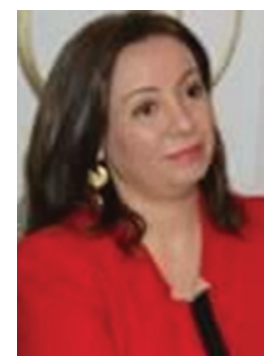

Dr. Hanen Khanchel is an Assistant Professor within the management department at the Institute of Advanced Business Studies (IHEC), University of Carthage, Tunisia. She is an active member and researcher of LIGUE (University of Manouba, Tunisia). Dr. Khanchel is passionate about multi-disciplinary approaches for complex problem solving. Her main research interest includes: Human Resource Management, Strategic Management, Leadership, Learning. Dr. Khanchel is a highly regarded author, with many research articles published in international journals.

${ }^{*}$ Corresponding author: Hanen Khanchel, IHEC, University of Carthage, Tunisia, LIGUE, University of Manouba, Tunisia. E-mail: Hanen.Khanchel@gmail.com.

\section{Introduction}

The COVID-19 pandemic is putting pressure on workers in ways that test not only their well-being and privacy, but also that of our society. The World Health Organization (WHO) found that $45 \%$ of health employees in China suffer from stress, while the prevalence of burn-out in Ethiopia tripled in April alone. The Coronavirus has created a mandate and an opportunity for us to expand our mental health offering. Long before COVID-19, Zurich realized that there were an increasing number of challenges in the workplace and the working environment, which led it to develop a global wellness framework. According to an investigative survey published in January 2017 by 
the TAP agency in Tunisia, 98\% of long-term leaves in the public service are linked to illness psychiatric patients and generate a loss for the State estimated at 172,000 working days per year. This is the equivalent of 4.6 million dinars of losses per year: "In the months that followed the revolution, the number of consultations increased by $20 \%$ at Razi Hospital, in Manouba and suicide attempts have almost quintupled" [1].

Another survey published in 2017 and conducted on a sample of 300 people representative of Ariana governorate, showed that the prevalence of at least one psychiatric disorder was $52 \%$. Compared to 2005 , this survey finds a slight decrease for depressive disorders $35 \%$ vs. $31 \%$ and anxiety disorders from $37 \%$ to $33 \%$. The increase in prevalence has been discreet for pipes addictive and more significant for psychotic syndromes and risk suicidal".

Finally, according to the latest Global Happiness Report, World Happiness Report (WHR) of the OECD, Tunisia is positioned, in 2020; at the 128th place in the world out of 153 countries in terms of citizen, happiness in 2017 it was ranked 102nd rank [2].

Regarding COVID-19 specifically, a study targeting 900 Tunisians showed that " $40 \%$ of them do not consider this disease to be serious. $65 \%$ underestimate the speed and severity of the contagion" ... this "could explain their careless, negligent, even deviant and irresponsible behavior". A recent study revealed the negative effects of quarantine on the mental health of citizens [3]. These include the onset of symptoms of post-traumatic stress disorder, confusion and anger. This study shows, in particular, that when the date of the end of containment is not defined, the psychological impact is greater. These uncertainties and these abrupt changes create an entirely new and difficult climate to manage. Another search that focused on the effects of population containment showed that mass quarantine is likely to arouse community anxiety, for many reasons:

- This measure shows that the authorities consider the situation to be serious and likely to get worse;

- The implementation of this constraint mainly for the benefit of those who found outside affected cities reduced confidence;

- The belief that the authorities are acting in the interests of those who are inside;

- Quarantine means loss of control and a feeling of being trapped, who will be strengthened if families are separated;
- Rumors play an important role: the desire to know the facts will intensify and the absence of clear messages will increase fear and push people to seek information from less reliable sources.

- High anxiety leads to rapid congestion of health services with patients who do not necessarily carry the virus.

- The confinement of some zones also ergonomic risk creating a stigmatization of their inhabitants, who are socially rejected, discriminated against in their workplace and who may suffer violence and attacks targeting their property.

Many programs have found a natural resonance in the COVID-19 situation, especially those aimed at supporting mental health. During the Tackle, Your Feelings program in Ireland and Australia, athletic models reinforce the message "there is nothing wrong with not going" [4]. Other programs have also known international success such as the best places to work program, this program allows the certification of the best employers. Indeed, participation in the Best Places to Work For program will allow companies to increase the motivation of their employees and to measure their level of satisfaction and commitment [5].

Many firms will be rebalancing their priorities in the coming months, so that resilience becomes just as important to their strategic thinking as cost and efficiency. Likewise, the weight of global competition and demographic change will continue to affect the way people balance their family and professional life [6]. These new trends have made the labor market more dynamic and have brought with them the emergence of more varied forms of work and new jobs, requiring new skills. They also have the potential to contribute to the widening of gender inequalities and to question the measures taken by the state for a long time [7]. Thus, the regulatory frameworks and solidarity practices established on the labor market may need to be adapted to ensure the sustainability of the welfare state and to guarantee adequate protection for employees during the COVID-19 pandemic [8]. The multiple definitions of these innovative practices are marked by a certain plasticity. For [9] only teamwork is the subject of a consensus as an innovative managerial practice. However, [10] do not include it in what they call "innovative practices" in which, on the other hand, we find versatility, flexibility, participation, quality standards and computerization. 
For others, "performance management" is based on the four essential innovations of working in autonomous teams, the existence of quality circles, incentive compensation and training [11]. According to [12], author has a more extensive conception of what he calls the "performance paradigm" and which combines two generic sets, namely "alternative work practices" and "employee involvement" practices.

These changes are often presented as part of a logic of exceeding taylorian work organizations, characterized in particular by their double vertical and horizontal division of work, which results in the strong prescription and fragmentation of tasks. The implementation of teamwork, information sharing, participation in decision-making or even the reduction of the prescription of work would contribute to this overshoot [13]. Incentives such as the systematic use of bonuses sometimes double the managerial systems aimed at increasing employee involvement. High Performance Workplace Organizations would be beneficial to employees, who would have the opportunity to mobilize their knowledge, express their creativity or even enhance their skills as in businesses. Most economic studies conclude that the productivity has improved following the adoption of innovative practices across Spanish regions [14].

However, in the field of critical sociology and philosophy, the spirit of these innovative practices has often been summed up as a "putting to work of subjectivity" which the principles of scientific organization aimed on the contrary to oust [15]. Several authors have thus seen in the wake of the "knowledge economy" an ability of capitalism to survive by the "total mobilization" of workers [16], their "second degree exploitation" [17] or the "managerial superhumanization"[18].

The invention of the concept of constrained autonomy reflects the contradictions between a logic of "liberation" from work and a logic of submission through the control of the resources made available to work. Therefore, after having long opposed the real importance and scope of the post-Taylorist devices, sociologists have today reached a minimal consensus, which can be summed up using two propositions. A new ergonomic framework has now been imposed, the main characteristic of which is to grant more autonomy to employees while placing them in a situation of increased stress [19].

In fact, the study whose empirical foundations find their source in ergonomic survey data clearly reflect the ambivalence of the effects of this health crisis on the work experience of employees. According to [20], authors summarize the state of the field by describing on the one hand the current of "mutual gains", for which employers and employees are also beneficiaries of the introduction of these innovative practices, and on the other the "critical perspective" whereby profits are made by companies to the detriment of their employees. Other authors prefer to suggest an opposition between "the motivation hypothesis" and "the intensification hypothesis". For the first, enrichment of work increases satisfaction and therefore motivation, while the second describes enrichment as an intensification, which decreases job satisfaction [21].

The purpose of this paper is to present a model of safety workplace innovative practices, which focuses on working conditions as well as quality of live at work, health and well-being in Tunisia. Its validation is based on data collected from the database of best places to work; whose findings highlight the decisive role of recognition in the construction of occupational health in a COVID-19 context. This manuscript is organized in two parts. Firstly, we present the theoretical foundations of this model, and then the describtion of the ergonomic methods used to develop this instrument. In the second part we discuss the results of the empirical analyzes, before explaining the ergonomic implications and future research proposed in the end.

\section{Conceptual framework}

"Participation" is often described as being at the heart of the changes that took place in the 1980s in Europe and the United States [22]. However, [23] recall that "when we observe the new practices actually implemented, their underlying rationality is not always as obvious as what the theoretical models suggest".

In addition, the theme of participation, in the broad sense of the means available to employees to influence their activity and their work situation [24]. However, this theme is far from being presented under the seal of the evidence so much the very term is charged with an ambivalent meaning and has been the subject of conflicting uses [25]. The innovative practices that are put under this suitcase depend not only on the actors but also on the national contexts [26].

The distinction between direct and indirect participation is quite clear, these two forms being regularly presented as opposite or competitive [27]. The first, which will be discussed in this manuscript, 
concern situations in which employees are personally involved in decisions concerning their activity, while indirect participation qualifies the influence that employees exercise through representatives, notably union representatives [28].

According to [24] beyond schools and disciplines, there is a striking consensus around the idea that employee participation is important for the quality of work, the nature of forms of direct participation does not is no less controversial. The sociologist thus recalls that the neo-Marxian perspective values the control of employees over the task while from the management point of view it is mainly semi-autonomous teams and the reinforcement of communication between supervisors and their subordinates who count [29].

Although the effects of digital transformation on the quality of work are contrasted, there is a consensus around the beneficial nature of those of participation, despite the ergonomic risks which are possibly associated in terms of longer working hours, work intensity and long-term endangerment of physical and mental health [29]. Thus, from data representative of British employees, Gallie concludes that the effects of autonomy are both stronger and more significant than those of managerial consultation on psychological well-being at work [29].

The conclusions of [24] at European level are similar: participation in the task and in the organization of work have positive effects on health and well-being at work. The authors show in fact that in the organizations that provide the most control over work, employees less often consider that they are risking their health and safety at work, declare the highest levels of psychological well-being and lowest rates of stress and absenteeism.

Participation would therefore be essentially a factor of health at work within the framework of the "Scandinavian socio-technical model" characterized by self-control and the weakness of rhythm constraints. The concomitance in the Nordic countries of high levels of participation and health at work could thus give the impression of a direct relationship between these two variables, which would be valid whatever the organizational context. In [24] is shown in fact that the Nordic countries Denmark, Sweden and Finland stand out clearly from the other European countries in terms of participation. According to the authors, the countries of the continental group Austria, Belgium, France, Germany, Luxembourg and the Netherlands are thus wrongly perceived as models of employee involvement since they much less often have the feeling of being able to influence the way of doing their work [24].

By taking the case of employees in the private sector in Tunisia during the COVID-19 pandemic, we would like to extend these reflections here by introducing recognition into the relationships between participation and health at work. Does greater control over work improve health? Is it not rather, when participation supports recognition that it contributes to the process of building occupational health?

Three sets of indicators are necessary, and in the present research were retain the same measures as proposed in [24] which is a report on the involvement of employees where the levels of task, organization and strategy are distinguished. The latter, in line with the perspectives described above, perceive participation as the result of multiple determinants having consequences on the learning of new things at work, the motivation of employees, the improvement of working and employment conditions well-being at work, as summarized in Fig. 1.

\section{Methodology}

The methodology is based on a neutral and objective study of the Tunisian company's innovative practices. The Best Places to Work for in Tunisia program is an initiative of the Best Companies Group USA Institute in various countries around the world, in partnership with several local institutional organizations which pays tribute to Tunisian companies offering the best working environment and which know how to attract and retain the best employees [5]. The ranking of the best employers is made based on a neutral and objective study carried out among a significant sample of employees of companies all sizes included who answer a questionnaire on their perception of their working conditions during the COVID-19 pandemic, the culture of the company, Human Resource management, development and professional recognition. This survey is supplemented by an ergonomic assessment of innovative practices within the Tunisian company. Ergonomic assessment survey is important to measure the ergonomic risk factors and evaluate the risk level of ergonomics exist in the working environment during the COVID-19 pandemic.

Once the data extracted from the report of the best places to work for in Tunisia program, it was a question of selecting the questions to represent the four recognition registers to test the solidity of the study by using a factorial analysis. In total, nine questions 


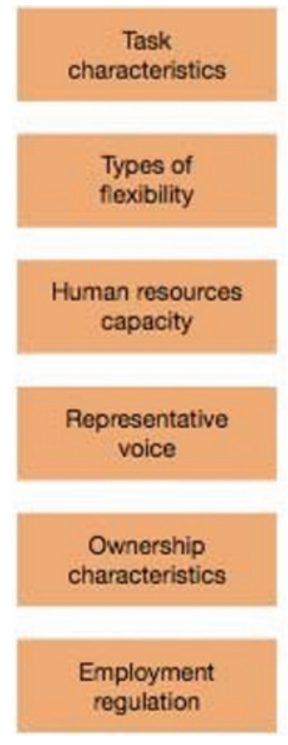

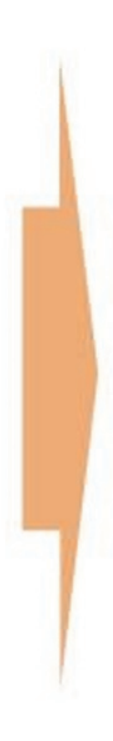
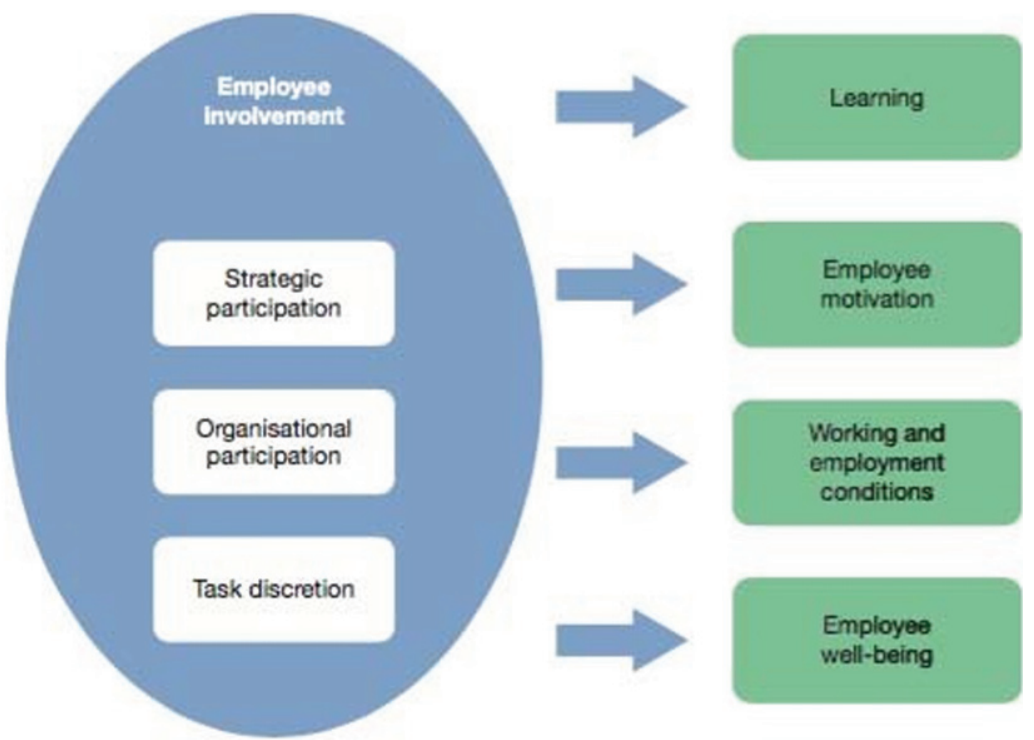

Fig. 1. Determinants and consequences of the participation [24].

likely to represent, albeit imperfectly, the recognition registers have been preserved.

Since the analyzes have so far focused only on employees in the private sector in Tunisia, our sample excludes the self-employed as well as employees in the public sector. To select these questions, we returned to the study where the systematic coding of the interviews allowed us to distinguish four major registers in which recognition expectations are expressed, then, through an analysis of the material, to propose some of the problems specific to each of these registers.

\subsection{Design of the survey}

The participation indicator at the task level includes three questions to which respondents could answer yes or no:

- Are you able to choose or change the order of your tasks? Yes/No

- Are you able to choose or change your working methods? Yes/No

- Are you able to choose or change your work rate or speed? Yes/No

In terms of participation in the organization, two questions are retained:

- Can you influence the decisions that are important to your work? (never, rarely, sometimes, most of the time, always)
- Are you involved in improving the work organization or work processes of your department or organization? (never, rarely, sometimes, most of the time, always)

Following the conclusions presented in [24] that were shown from a factorial analysis, the items selected belong to two dimensions, and two health indicators were constructed from the answers to the following question:

"During the COVID-19 pandemic, have you suffered from one or more of the following health problems?" The physical health indicator physical variable includes the following items:

- Hearing problems,

- Skin problems,

- Back pain,

- Muscle pain in the upper limbs, neck and / or upper limbs,

- Muscle pain in the lower limbs,

- Headache, eyestrain,

- Stomach pain,

- Lower respiratory tract infections,

- Cardiovascular illnesses,

- Injurys.

For the construction of the psychic health indicator psychic variable, the following items were retained:

- Depression or anxiety,

- General fatigue,

- Insomnia. 
In the research presented by [24], authors use a single health indicator in addition to the subjective well-being and absence indicator. We preferred to make a distinction, which roughly overlaps with that which separates musculoskeletal disorders (MSD) from psychosocial risks (PSR), the first constituting, as [30] recall the "first cause of occupational disease". "While the second" fall under priority actions in occupational health policy.

By using an ergonomic measure that is more related to physical health and another more related to mental health, we are not ignoring the now established interactions that unite these two dimensions [31]. In 2013, the interdisciplinary perspectives on work and health journal devoted to an issue of "MSDs and psychosocial factors" which highlights the links between work stress, mental repression and musculoskeletal disorders [32] and shows that the organization of work affects both physical and mental health. Intensification of work is notably a factor in MSD, along with the repetitive nature of work:

"Old practice, repetitive work cannot alone explain the MSD observed during the COVID-19 pandemic. It can be considered as a sign of the intensification of work. Epidemiologists blame the worsening of time constraints, in office jobs as on some industrial positions. The urgency forced to operate in the fastest way, always using the same muscles; or to intervene in awkward postures at the cost of intense punctual efforts. The reduction in informal break times is particularly harmful. Finally, the tension caused by time pressure plays a role in the appearance of pathologies by itself.

However, it is a question of promoting a joint approach to prevention of MSDs and RPS, in particular with regard to the search for "organizational determinants that can be at the origin of intense physical and mental stresses in the workplace [33].

\subsection{Sample size}

Multi-stage sampling was used in this study. The main purpose of multi-stage sampling is to select samples, which are concentrated in a few geographical regions [34]. Once again, this saves time and money. First, positive sampling was used to select the first five Tunisian companies, using secondary data from the report of the "Best Places to Work For" in Tunisia program. 100 private sector employees were identified 20 from each of the selected companies. Simple random sampling was used to reach
Table 1

Summary of the distribution of indicators

\begin{tabular}{lcccc}
\hline Indicators & Min & Max & Average & $\begin{array}{c}\text { Standard } \\
\text { deviation }\end{array}$ \\
\hline Task & -1.43 & 1.02 & 0.00 & 1.00 \\
Organization & -1.44 & 1.90 & 0.00 & 1.00 \\
Recognition & -3.97 & 1.97 & 0.00 & 1.00 \\
Physical & -1.21 & 3.78 & 0.00 & 1.00 \\
Psychic & -1.03 & 2.01 & 0.00 & 1.00 \\
\hline
\end{tabular}

the sample of selected companies. The desired sample size was determined according to the formulations in [35] and [36]. Since there is no estimate available of the proportion of the target population assumed to have the characteristics of interest, $50 \%$ was used. In this survey, the target proportion of the population was assumed to have the characteristics of firms certified the best places to work, which are companies that use innovative practices for safety, health and well-being at work in Tunisia.

\section{Result}

We first present the findings of the survey, which allowed us to measure the dimensionality of the constructs and the internal consistency of these scales. Then, we report the results of the factor analysis, which allowed us to visualize the effect of different determinants on our variable of interest. Finally, we will interpret the results obtained in this study. Table 1 summarizes the distribution of the five indicators that will be used to study the relationships between health, participation and recognition.

Moreover, it is a question of specifying the nature of the relationships between multiple variables, the literature having notably emphasized that the terms "moderator" and "mediator" were used without distinction [37].

However, from the point of view that we have of a phenomenon, the distinction between a moderating variable and a mediating variable is essential. Indeed, a moderation model supposes on the one hand a direct relation between $\mathrm{A}$ and $\mathrm{B}$ and on the other hand, admits the existence of other variables, which can influence the direction and this, is typically the case for variables such as gender, age or socioprofessional category, which modify the effect of A or B. 
Thus, giving employees more control over their work would promote their health because it would put them in favorable conditions for building a feeling of recognition. In our case, a "full mediation" model therefore requires that four conditions could be satisfied [38]:

- There exists an effect of participation on health: $c$;

- Participation has an effect on recognition: $a$;

- Recognition has an effect on health: $b$.

It is rare that the relationship between A and B, c' disappears completely when we consider the mediating role of a third variable. When direct effect persists, even if it has weakened, we speak of "partial mediation". Thus, "while a partial mediation is less impressive than a complete mediation, it nevertheless gives us a theoretical indication on how the independent variable affects the dependent variable" [38].

If there were a direct effect between participation and health at work, it would remain to consider the hypothesis of a moderator effect of recognition, which would positively modulate the effects of a greater implication in work on health employees.

Schematically, the mediation model represents health as a process where a greater grip on work promotes the construction of the feeling of recognition, which is considered as a determinant of health. The recognition-moderation model assumes that participation is a direct determinant of health. In this case, recognition would reinforce the positive effects of participation, or reduce the deterioration of health. In summary, "the moderators rather represent internal or external characteristics which are antecedent to the process studied, while the mediators reveal it in its temporal dimension" [37].

Developed at the University of Ghent, notably by Rosseel, the lavaan library enables structural equations to be produced quite simply, representing both mediation and moderation relationships [39]. Thus, we were able to confirm the hypotheses of recognition as a mediator and as a moderator of the relationship between health and participation in work.

Before to describe the results obtained for these three models, let us add that variables were introduced to consider the characteristics of individuals and their employers, whose role was underlined in the central part of the study. Therefore, gender, age, seniority, length of contract, diploma, profession, and sector was retained as variables for "control".

\section{Discussion}

The results obtained concerning the effect of participation on health show that in Tunisia during the COVID-19 pandemic, more participation does not imply being in better health, neither physical nor mental since no coefficient is negative. On the contrary, participation at the task level seems to have a rather negative impact on mental health.

The absence of coefficients suggesting a directly positive relationship between participation and health in this model invites doubts, for employees in the private sector, of the reality of the "win-win" model where it would increase the grip of employees on their work so that their health improves. This result is consistent with French work on increasing mental load [43], which results at least in part from "companies are calling on the initiative of their employees more than in the past to better respond to customer demand and to improve their productivity. The counterpart of this greater responsibility and this greater involvement in the company is a relative increase in mental load at work" [41].

However, this result is problematic regarding the theoretical definition of the mediation model proposed by Baron and Kenny [49]. A mediation model supposes an effect and that one can measure, in the simple model, a significant effect between the two terms studied. Hence, our first results are either not significant, or in the opposite direction to that expected.

Therefore, we can make the hypothesis, largely compatible with the literature, of the existence of contradictory effects of participation on health according to the organization and working conditions [42]. In fact, the increase in mental load that accompanies the greater involvement of employees has ambivalent effects on health: "The impact of the feeling of responsibility can be positive, if the employees feel valued, and their work is enriched, or negative, when the mental load becomes source of stress, itself creator of pathologies [43]. The mental burden as identified in the survey therefore does not prejudge the pathogenic nature or not of the stress perceived by the employees" [41].

Our initial hypothesis that the links between participation and health are positive if they are part of a process that improves recognition. Then, it would be verified if the introduction of mediation made this direct effect meaningful. Mediation through recognition would play the role of revealing the direct effect of participation on health. 
Table 2

Comparative table of effects participation in health with and without mediation

\begin{tabular}{lccc}
\hline Psychic health & $M 1$ & $M 2$ & $M 3$ \\
\hline Task & 0.076 & 0,108 & 0,107 \\
Organization & 0.032 & 0,082 & 0,083 \\
Recognition & & 0.330 & 0,327 \\
Recognition * Task & & & 0.039 \\
Recognition * Organization & & & 0.021 \\
Physical health & & & \\
Task & 0.045 & 0,071 & 0,069 \\
Organization & 0.056 & 0,034 & 0,036 \\
Recognition & & 0.259 & 0,254 \\
Recognition * Task & & & 0.059 \\
Recognition * Organization & & & 0.035 \\
Recognition & & & \\
Task & & 0.099 & 0.099 \\
Organization & & 0.347 & 0.347 \\
\hline
\end{tabular}

The results of the mediation model described are reported in column M2 of the Table 2. They largely confirm this hypothesis since most of the direct effects of participation on health become significant.

As in the simple model, the effect of participation at the level of the task on mental health is negative but this time it is stronger and significant only by $1 \%$. The direction of the relationship between organizational participation and mental health changes meaning and becomes significant. Thus, while no coefficient was significant for physical health, participation at the task level appears to have a rather negative effect on health when the mediating role of recognition is considered. The link between organizational participation and physical health points in the same direction but is not significant.

The effects expected in the mediation model are all obtained. On the one hand, the two forms of participation, represented by the letter a, have positive and significant effects on recognition, especially regarding participation at the organizational level. As a reminder, this indicator includes both the influence that the employee considers having on the important decisions concerning his work and in the improvement of work organization or work processes of the service.

On the other hand, the expected effects of recognition on physical and mental health are clearly confirmed. With high and significant coefficients, recognition is indeed an important factor in occupational health. However, we recall that our recognition indicator, conceived as the sum of the scores in each of the dimensions of the factor analysis, reports on the degree of satisfaction of recognition expectations in the registers of activity, relationships, reward and of the person. The strength of the link observed therefore underlines the importance of the possibility of establishing a positive relationship with oneself in the construction of health.

A last model was tested to explore the hypothesis of the effect and moderator of recognition. However, the literature review suggests that recognition, in the form of a good word from the superior, for example, could compensate for the deleterious effects of increased involvement. In this case, one might expect that the effects of participation at the task and organizational level, in interaction with recognition, would be significantly negative, that is, they indicate a decrease in health problems.

These results suggest that, in the case of employees'participation, apart from its role in building the feeling of recognition, is rather a factor of deterioration of health in the current state recognition obtained by employees.

The fact that in total the increase in the grip those employees have on their work is not synonymous with an improvement in their health during the COVID19 period according to the data studied. In fact, in the research of [24] authors show that on a European scale, employees who work in organizations where they feel they have control over their task less often report the feeling of stress (like [32]). On the contrary, the study concludes that the effects are not significant, or even negative in the case of the relationship between control over the task and mental health.

\section{Conclusion}

Participation would contribute to occupational health on the condition of being introduced in an organizational context favorable to recognition. Thus, in this research which aims to provide empirical elements to the controversy between critical perspectives and mutual gains, Kalmi and Kauhanen take great care to emphasize that they believe that the positive results they obtain are more to be put on account of the context as innovations in themselves. Therefore, the authors point out that transformations are more likely to be made for the benefit of employers as well as employees if the latter are strongly represented, are involved in co-determination, are protected against dismissals and if the company is marked by a high level of interpersonal trust [20]. 
With its centralized collective bargaining system, an important tradition in terms of participation, strong job security and, culturally, a high level of interpersonal trust, associated with a low perceived conflict between employees and employers, Tunisia seems to be a very different context from the other countries. Therefore, the model obtained leads to a hierarchy of the effects of the innovative practices on occupational health during the COVID-19 pandemic. These effects are unaltered by the process of digitalisation [44]. Ergonomic evaluations should be designed and tailored in such a way as to capture all relevant transformations in an adequate manner [45]. We do not provide a full ergonomic evaluation framework in this opinion, but we do reflect on important elements. Monitoring can also complement ergonomic evaluations by observing general trends in how health crisis evolves [46]. Therefore, we recommend starting any ergonomic assessment with a full description of the relevant innovative practices. Its use and aims, addressing elements like the ones above to give a full overview of this practices, its intended use, costs and consequences on occupational health, and its most relevant comparator, to be able to select an appropriate ergonomic assessment strategy and key outcomes to include. Furthermore, important frameworks and practical guides for this ergonomic assessment must be proposed in futur research. These can serve as a starting point both for practical ergonomic assessment studies and for further development of ergonomic assessment frameworks. In ergonomic assessment, the development phase of the digital transformation as well as implementation of the innovative practices, are crucial elements in health crisis [47]. Combinations of different ergonomic assessment devices may be required to provide relevant data to decision makers at different contexts. Careful selection and justification of the innovative practices is warranted.

\section{References}

[1] World Health Organization (WHO). Situation report, 18. Feb 7 2020. [Online] Available: https://www.who.int/docs/ default-source/coronaviruse/transcripts/transcript-corona virus-press-conference-full-7feb2020-final.pdf?Sfvrsn= 3beba1c0_2, [Accessed November 25, 2020].

[2] OECD, World Happiness Report, (WHR), [Online] Available: https://www.tunisienumerique.com/tunisie-epi demie-du-coronavirus-les-aspects-psychologiques, [Accessed November 25, 2020].

[3] Brooks, Samantha K, PhD; Rebecca K Webster, PhD; Louise E Smith, PhD; Lisa Woodland, MSc; Prof Simon
Wessely, FMedSci; Prof Neil; Greenberg, FRCPsych; et al. The psychological impact of quarantine and how to reduce it: rapid review of the evidence, The Lancet. 2020; 395(10227):912-920.

[4] The Z Zurich Foundation, (ZZF), [Online] Available: https://www.tackleyourfeelings.com/, [Accessed November 25, 2020].

[5] The global workplace research firm, Best Companies Group (BCG) USA. [Online] Available: https://bestplacesto workfor.org/steps-to-certification, [Accessed November 25, 2020].

[6] Khanchel H, Kahla KB. Representation of the Articulation between Spheres of Life. Business and Management Research, 8, 10. DOI: 10.5430/bmr.v8n2p10, 2019a

[7] Al-Jedaiah M. Gender Inequality and Human Resource Management (HRM) Practices in Jordanian Commercial Banks. International Journal of Human Resource Studies. 2020;10:369. DOI: 10.5296/ijhrs.v10i1.16178.

[8] Khanchel H. Regulation of Social Times during the COVID19 Period: A Replication and Extension of the Work Activity Regulation Model, Business and Management Research, Business and Management Research, Sciedu Press. 2020;9(3):14-24.

[9] Osterman, P. Work Reorganization in an Era of Restructuring: Trends in Diffusion and Effects on Employee Welfare. Industrial and Labor Relations Review. 2000;53(2):179-96.

[10] Askenazy P, Eve C. Innovative Work Practices, Information Technologies, and Working Conditions: Evidence for France. Industrial Relations. 2010;49(4):544-65.

[11] Appelbaum E, Hoffer Gittel J, et C. Leana. HighPerformance Work Practices and Sustainable Economic Growth. Center for Economic and Policy Research Report. 2011.

[12] Godard J. A Critical Assessment of the High-Performance Paradigm. British Journal of Industrial Relations. 2004; 42(2):349-78

[13] Green F, Steven McIntosh. The intensification of work in Europe. Labour Economics. 2001;8(2):308-291.

[14] García-Pozo A, Campos Soria J, Nuñez A. Technological innovation and productivity across Spanish regions. The Annals of Regional Science. 2021;67:167-187. DOI: 10.1007/s00168-020-01044-9.

[15] Gallie D. Welfare Regimes, Employment Systems and Job Preference Orientations. European Sociological Review. 2007;23(3):279-93.

[16] Rebecca E, Ulrike D, Lars-Erik M. Moving on up in the information society? A longitudinal analysis of the relationship between Internet use and social class mobility in Britain. The Information Society. 2018;34(5):316-27.

[17] Lallement M. Régulation des temps sociaux en France et en Suède. Economies et sociétés. 2002;(31):1349-67.

[18] Lallement M. L'emploi des sociologues. In Amélie Pouchet, dir. Sociologies du travail: quarante ans après, Elsevier, Amsterdam, Londres, 2001, pp. 173-190.

[19] Kadir B. Broberg O, Conceição C. Current Research and Future Perspectives on Human Factors and Ergonomics in Industry 4.0. Computers \& Industrial Engineering. 2019; 137:106004. DOI: 10.1016/j.cie.2019.106004.

[20] Kalmi P, Antti K. Workplace Innovations and Employee Outcomes: Evidence from Finland. Industrial Relations. 2008;47(3):430-59. 
[21] Khanchel H, Kahla KB. Job dissatisfaction and turnover crises in Tunisia, Business and Management Research. 2019;83:53-73.

[22] Pot F, Steven D, Oeij P. Social innovation of work and employment. In H.-W Franz, J. Hochgerner, et J. Howaldt, (dirs.), Challenge Social Innovation. Potential for Business, Social Entrepreneurship, Welfare an Civil Society, pp. 261274. Springer, Berlin. 2012.

[23] Greenan N, Jacques M. Les changements organisationnels, l'informatisation des entreprises et le travail des salariés. Revue économique. 2006;57(6):1137-75.

[24] Gallie D, Ying Z. Work organisation and employee involvement in Europe. Publications Office of the European Union, Luxembourg, 2013.

[25] Béroud S. Perspectives critiques sur la participation dans le monde du travail: éléments de repérage et de discussion. Participations. 2013;5:5-32.

[26] Wilkinson A, Paul JG, Mick M. The Oxford Handbook of Partici- pation in Organizations. Oxford University Press, Oxford. 2010.

[27] Lallement M. Sur les moyens de faire descendre la démocratie dans l'entreprise. In Odile Piriou et Pierre Lénel, (dirs.), Les états de la démocratie. Comprendre la démocratie au-delà de son utopie, pp. 51-70. Hermann, Paris. 2011.

[28] Kandathil G, Joseph J. Normative Underpinnings of Direct Employee Participation Studies and Implications for Developing Ethical Reflexivity: A Multidisciplinary Review. Journal of Business Ethics. 2019;157. 10.1007/s10551-0173689-x.

[29] Gallie D. Direct participation and the quality of work. Human Relation. 2013;66(4):453-73.

[30] Caroly S, Pascal S, et Nicole Vézina. Marge de manøeuvre et pouvoir d'agir dans la prévention des TMS et des RPS. Le travail Humain. 2015;78(1):1-8.

[31] Dufour C, et al. Occupational Health and Safety Division of Responsibility: A Conceptual Model for the Implementation of the OHSAS 18001:2007 Standard. 1 Jan. 2020:549-63.

[32] Betke K, Basińska M, Andruszkiewicz A. Sense of Coherence and Strategies for Coping with Stress among Nurses. DOI: 10.21203/rs.3.rs-91555/v1. 2020

[33] Popescu S, et al. A Structured Framework for Identifying Risks Sources Related to Human Resources in a 4.0 Working Environment Perspective. 2020:511-27.

[34] Ackoff RL. Statistics in Operations Research and Operations Research in Statistics. McCloskey J. F. \& Trefethen F. N., eds. in Operations Research for Management, 117-133. Johns Hopkins University Press: Baltimore. 1954.

[35] Fisher RA. Statistical Methods and Scientific Inference, 3rd ed. London: Hafner Press. 1973.
[36] Riungu C, Njehia B, Mutai B. Effects of supermarkets on fresh fruit and vegetables small-scale farmers in central Kenya. Sky Journal of Business Administration and Management. 2013;15:47-58.

[37] Rascle N, Sandrin I. Médiateurs et modérateurs: implications théoriques et méthodologiques dans le domaine du stress et de la psychologie de la santé. Le travail Humain. 2001;64(2):97-118.

[38] Brauer M. L'identification des processus médiateurs dans la recherche en psychologie. L'année psychologique. 2000;4:661-81.

[39] Rosseel Y. lavaan: An R Package for Structural Equation Modeling. Journal of Statistical Software. 2012;48(2): $1-36$.

[40] Dares, Reprise de l'intensification du travail chez les salariés. DARES Analyses. 2014;49:1-11.

[41] Hamon-Cholet S, Catherine R. La charge mentale au travail: des enjeux complexes pour les salariés. Économie et statistique. 2000;339-340:243-55.

[42] Valeyre A. Les conditions de travail des salariés dans l'Union européenne à quinze selon les formes d'organisation. Travail et Emploi. 2007;112:35-47.

[43] Islam M, Alam W, Keramat S, Murshid M, Haque R, Kabir E, et al. Working conditions and occupational stress among nurses in Bangladesh: a cross-sectional pilot study. Journal of Public Health. 2021. DOI: 10.1007/s10389-020-01415-8.

[44] Pfaffinger K, Reif J, Spiess E, Berger R. Anxiety in a digitalised work environment. 2020;1-11. DOI: $10.1007 /$ s11612-020-00502-4.

[45] Brito M, Vale M, Leão João M, Pinto Ferreira L, Gonçalves M. Lean and Ergonomics decision support tool assessment in a plastic packaging company. Procedia Manufacturing. 2020;51:613-619. DOI: 10.1016/j.promfg.2020.10.086.

[46] Felekoglu B, Tasan, S. Interactive ergonomic risk mapping: A practical approach for visual management of workplace ergonomics. International Journal of Occupational Safety and Ergonomics. 2020;1-41. DOI: 10.1080/10803548.20 20.1712127.

[47] Yu Y, Yang X, Li H, Luo X, Guo H, Fang Qi. Joint-Level Vision-Based Ergonomic Assessment Tool for Construction Workers. Journal of Construction Engineering and Management. 2019;145. DOI: 10.1061/ASCECO.19437862.0001647 .

[48] Li Y, Ho B, Hara T, Ota J. Automatic Assessment System of Operators' Risk in Order Picking Process for Task Analysis. DOI: 10.1007/978-3-030-39512-4_47.2020.

[49] Baron RM, Kenny DA. The moderator-mediator variable distinction in social psychological research: Conceptual, strategic, and statistical considerations. Journal of Personality and Social Psychology. 1986;51:1173-82. 